DOI: http://dx.doi.org/10.19177/reen.v9e1201658-94

http://portaldeperiodicos.unisul.br/index.php/EeN/index

\title{
A INFLUÊNCIA DAS CARACTERÍSTICAS CULTURAIS BRASILEIRAS NA NEGOCIAÇÃO INTERNACIONAL
}

\section{THE INFLUENCE OF BRAZILIAN CULTURAL CHARACTERISTICS ON INTERNATIONAL NEGOTIATION}

\section{LA INFLUENCIA DE CARACTERÍSTICAS CULTURALES BRASILEÑAS EN LA NEGOCIACIÓN INTERNACIONAL}

\section{Monique Gaviraghi}

Graduada em Comércio Internacional pela Universidade de Caxias do Sul (UCS) Endereço: R. Francisco Getúlio Vargas, n. 1130, CEP: 95070-560. Caxias do Sul, RS, Brasil Telefone: (54) 3218-2100

E-mail: monique.gaviraghi@hotmail.com

\section{Fernanda Lazzari}

Doutora em Administração na Área de Marketing pela Universidade Federal do Rio Grande do Sul (UFRGS)

Endereço: R. Francisco Getúlio Vargas, n. 1130, CEP: 95070-560. Caxias do Sul, RS, Brasil

Telefone: (54) 3218-2100

E-mail: fernandalazzari@hotmail.com

\section{Gabriel Sperandio Milan}

Doutor em Engenharia de Produção na Área de Sistemas de Qualidade pela Universidade Federal do Rio Grande do Sul (UFRGS)

Professor e pesquisador da Universidade de Caxias do Sul (UCS)

Endereço: R. Francisco Getúlio Vargas, n. 1130, CEP: 95070-560. Caxias do Sul, RS, Brasil

Telefone: (54) 3218-2100

E-mail: gsmilan@ucs.br 
Artigo recebido em 19/07/2015. Revisado por pares em 22/09/2015. Reformulado em 27/02/2016. Recomendado para publicação em 28/03/2016, por Ademar Dutra (Editor Científico). Publicado em 30/04/2015. Avaliado pelo Sistema double blind review.

\section{RESUMO}

Este estudo analisou as principais características culturais brasileiras e seu impacto na negociação internacional. O método escolhido para operacionalizar a pesquisa foi o estudo qualitativo-exploratório, com a aplicação de entrevistas individuais, sendo quatro delas realizadas com experts e outras oito com negociadores de diversas nacionalidades, que têm frequente contato com a cultura e executivos brasileiros. Fatores culturais como distância de poder, coletivismo, nepotismo, aversão à incerteza, orientação de curto prazo, proximidade espacial, complexo de inferioridade e religiosidade são características presentes na cultura brasileira e que podem causar alguma influência na negociação que envolve a interação com pessoas de diferentes nacionalidades.

Palavras-chave: Cultura; Cultura Brasileira; Características Culturais; Estratégia; Negociação Internacional.

\section{ABSTRACT}

This study analyzed the main Brazilian cultural characteristics and their impact on international negotiations. The method chosen to develop the research was a qualitativeexploratory study with the application of individual interviews, four of them held with experts and eight others with negotiators from different nationalities that have frequent contact with the Brazilian culture and executives. It was evidenced that cultural factors, such as large power distance, collectivism, nepotism, high uncertainty avoidance, short-term orientation, spatial proximity, inferiority complex and religiosity, are characteristics present in the Brazilian culture and that can influence negotiations which involve interaction among people from different nationalities.

Keywords: Culture; Brazilian Culture; Cultural Characteristics; Strategy; International Negotiation.

\section{RESUMEN}

En este estudio fueron analizadas las principales características culturales brasileñas y su impacto en la negociación internacional. El método elegido para esta investigación fue el estudio cualitativo-exploratorio con uso de entrevistas individuales: cuatro realizadas con experts y otras ocho con negociadores de diversas nacionalidades que tiene frecuente contacto con la cultura y ejecutivos brasileños. Factores culturales como distancia del poder, colectivismo, nepotismo, aversión a la incertidumbre, orientación de corto plazo, proximidad espacial, complejo de inferioridad y religiosidad son características presentes en la cultura brasileña e que pueden causar alguna influencia en la negociación que involucra la interación con personas de diferentes nacionalidades.

Palabras-clave: Cultura; Cultura Brasileña; Características Culturales; Estratégia; Negociación Internacional. 


\section{INTRODUÇÃO}

Devido à intensificação do processo de globalização, a partir da liberalização dos mercados, da redução das barreiras ao comércio e aos investimentos e da velocidade nos avanços em tecnologia e nos transportes, as relações comerciais entre empresas de distintos países vêm se tornando algo cada vez mais comum. Tentadas pela oferta de vender seus produtos em novos mercados ou de buscar fontes de abastecimento mais baratas no exterior, as empresas cada vez mais frequentemente buscam a internacionalização (CAVUSGIL; KNIGHT; RIESENBERGER, 2010; CULLEN; PARBOTEEAH, 2010; VAN TULDER, 2013).

No Brasil, o início da década de 90 marcou o fim do protecionismo no país. A abertura comercial ocorreu através da redução de tarifas de importação e do aumento dos incentivos às exportações, fazendo com que os fluxos comerciais com outros países tenham aumentado (MDIC, 2008). Neste cenário, surge a demanda por negociadores internacionais, profissionais que devem buscar conhecer não apenas a sua própria realidade, também a dos seus parceiros de negócios (ANG; TEO, 1997; KHAKHAR; RAMMAL, 2013). Negociar com empresas de países estrangeiros requer a compreensão das questões culturais, políticolegais e econômicas destes países (CULLEN; PARBOTEEAH, 2010; TJEMKES; VOS; BURGERS, 2012). Aliás, os aspectos culturais têm grande influência no processo de interação entre pessoas de diferentes nacionalidades, pois a cultura pode definir a maneira como os indivíduos pensam, agem e se comunicam (SHIMUTWIKENI, 2011). Compreender as diferenças culturais é essencial em uma negociação internacional, pois os métodos de negociação variam de uma cultura para a outra. As negociações internacionais são potencialmente mais complexas do que as negociações intraculturais, e quanto mais um negociador conseguir aprender sobre a estrutura cultural de outras nações, mais efetivas serão as negociações com os executivos provenientes destes países (MILES, 1995; HARRIS; CARR, 2008). 
Devido à sua grande dimensão geográfica, o Brasil apresenta uma notável diversidade cultural interna. A cultura brasileira é proveniente de três matrizes: indígena, portuguesa e africana. Estas três raças se misturaram e deram origem a várias subculturas no Brasil (MOTTA, 1997). Como define Freitas (1997, p. 42), "por ser híbrida em sua formação e, mais recentemente, ter assimilado culturas imigrantes diversas (...), a sociedade brasileira pode dar certa impressão de que vive em um país de imenso caos cultural". Mas, apesar da pluralidade de comportamentos e de símbolos, o núcleo central da cultura brasileira é o mesmo de Norte a Sul do país (FREITAS, 1997). Assim sendo, é possível a identificação de uma série de características culturais, ou fragmentos culturais, comuns a todas as regiões e que levam em conta a diversidade e a heterogeneidade do Brasil (MORELLI et al., 2002). Diante isso, foi estabelecida a seguinte questão central de pesquisa: de que forma as características culturais brasileiras influenciam na negociação internacional?

Com o objetivo de responder a esta questão, buscou-se identificar, sob o ponto de vista de experts em cultura e em negociação internacional e de negociadores estrangeiros, verificar os principais aspectos culturais que influenciam na negociação internacional, além de identificar as principais características culturais brasileiras, apontando quais são aquelas que afetam positivamente a negociação internacional e quais a afetam de maneira negativa.

Como as negociações internacionais são ainda mais multiformes do que as intraculturais, a relevância deste estudo está em proporcionar aos negociadores brasileiros uma fonte de informação que possam consultar ao se preparar para negociações internacionais, não tendo apenas que confiar em seus instintos ou técnicas aprendidas. Além do mais, tal abordagem é relevante devido à importância das negociações para as empresas e para as organizações, pois os profissionais que trabalham com negociações internacionais devem ser indivíduos esforçados em desenvolver habilidades voltadas para o comportamento social bem-sucedido com membros de outras culturas (CAVUSGIL; KNIGHT; RIESENBERGER, 2010). Por conseguinte, o presente estudo tem o potencial de ajudar as empresas a selecionar seus negociadores internacionais e prepará-los previamente às negociações, levando em consideração todas as particularidades envolvidas em uma relação intercultural.

\section{REFERENCIAL TEÓRICO}

Revista Eletrônica de Estratégia \& Negócios, Florianópolis, v.9, n.1, jan./abr. 2016. 


\subsection{INFLUÊNCIA DOS ASPECTOS CULTURAIS NA NEGOCIAÇÃO INTERNACIONAL}

De acordo com Cohen (2004), o principal objetivo da negociação é conquistar o apoio ou convencer pessoas de quem se deseja alguma coisa. Para tanto, é preciso ter clara compreensão das motivações de ambos os lados envolvidos no processo, uma vez que o outro lado deve se sentir bem com o resultado (ACUFF, 2008). Vale destacar que as negociações internacionais são revestidas de maior dificuldade, se comparadas às negociações em âmbito doméstico, pois o número de variáveis envolvidas é maior. Enquanto em uma negociação intranacional certos fatores como o clima político e econômico são, geralmente, os mesmos para as duas partes envolvidas, em uma negociação internacional estes aspectos podem ser distintos e muito impactantes para as partes (MARTINELLI; VENTURA; MACHADO, 2004).

Por isso é fundamental que o negociador internacional seja sensível ao ambiente e à cultura do país com o qual está negociando, adaptando sua perspectiva às diferentes realidades (HOFSTEDE; HOFSTEDE; MINKOV, 2010; WILKEN; JACOB; PRIME, 2013). Sendo assim, em uma negociação internacional deve-se considerar o ambiente do país com o qual se está negociando. Fatores como localização geográfica, cultura, burocracia das instituições governamentais, lei e governo variam de um país para o outro e, portanto, devem ser considerados como obstáculo a superar para que a negociação seja bem sucedida (CAVUSGIL; KNIGHT; RIESENBERGER, 2010; CZINKOTA; RONKAINEN, 2011).

A negociação internacional é um processo complexo, influenciado pela cultura dos indivíduos envolvidos, que se comportam de acordo com as atitudes e costumes herdados de sua cultura de origem. Indivíduos com a mesma herança cultural tendem a apresentar padrões comuns de pensar, sentir e reagir, resultando em um único comportamento consistente e, consequentemente, em uma negociação com um único estilo. Já na negociação internacional, que envolve indivíduos de diferentes nacionalidades, as diferenças culturais predominam e podem afetar o processo e seu resultado (SIMINTIRAS; THOMAS, 1998; ANG; TEO, 1997).

De acordo com Hofstede (1994), em seus vários anos de pesquisas em diversos países de todo o mundo, tornou-se possível a identificação de cinco dimensões que diferenciam as culturas nacionais. Tais dimensões impactam nas relações de qualquer Revista Eletrônica de Estratégia \& Negócios, Florianópolis, v.9, n.1, jan./abr. 2016. 
gênero entre indivíduos de diferentes culturas. São elas: distância de poder, individualismo versus coletivismo, masculinidade versus feminilidade, aversão à incerteza e orientação de longo prazo versus orientação de curto prazo. Mais recentemente, o pesquisador propôs uma nova dimensão, indulgência versus restrição (HOFSTEDE, 2013).

A distância de poder é representada pela medida em que os membros menos poderosos de uma organização aceitam que o poder e a riqueza sejam distribuídos de forma desigual (HOFSTEDE, 1994). Hofstede (1994) sugere que o nível de desigualdade de uma sociedade é endossado tanto pelos líderes quanto pelos seguidores, e que todas as sociedades são desiguais, mas algumas são mais desiguais que as outras. Quanto maior a distância de poder, menos interação haverá entre indivíduos de diferentes classes econômicas e sociais. Isto afeta as negociações internacionais, uma vez que os negociadores de culturas mais hierárquicas serão relutantes em negociar com indivíduos cuja posição é diferente da sua própria. O processo de negociação pode ser mais lento, pois geralmente será necessária aprovação de seus supervisores (SOBRAL; CARVALHAL; ALMEIDA, 2008). Negociadores provenientes de culturas nas quais há maior distância de poder são mais competitivos e adotam um estilo de negociação ganha-perde, no qual apenas uma das partes envolvidas na negociação tem resultado positivo. Para isso, estes negociadores exigem muitas concessões, mas não estão dispostos a retribuí-las. Além disso, utilizam abordagens agressivas para a resolução de conflitos, sempre tentando obter vantagem sobre os outros (LIN; MILLER, 2003).

A dimensão individualismo versus coletivismo refere-se aos graus em que os indivíduos são integrados em grupos. Nas culturas individualistas, os laços entre os indivíduos não são muito fortes e se espera que cada um cuide de si mesmo. Nas culturas coletivistas, as pessoas são integradas em grupos fortes e coesos, muitas vezes considerados uma extensão da sua própria família, protegendo uns aos outros em troca de lealdade. Nenhuma cultura se encontra no extremo do individualismo ou do coletivismo, mas em algum lugar entre os dois extremos. Conceitos de particularismo e universalismo também estão relacionados a esta dimensão. Particularismo é uma forma de pensar na qual o modo como uma pessoa é tratada depende do grupo ou categoria em que está inserida. No universalismo, todas as pessoas são tratadas de maneira igual (HOFSTEDE, 1994). Tal dimensão pode afetar as negociações, na medida em que negociadores provenientes de Revista Eletrônica de Estratégia \& Negócios, Florianópolis, v.9, n.1, jan./abr. 2016. 
culturas mais coletivas vão preferir decisões e processos de negociação que envolvam ambos os lados. Estes negociadores podem se mostrar mais abertos com os membros pertencentes à sua rede social e com certo grau de desconfiança com aqueles que não pertencem a ela (SOBRAL; CARVALHAL; ALMEIDA, 2008).

A dimensão masculinidade versus feminilidade contempla a distribuição de papéis entre os sexos. Os valores das mulheres diferem menos entre as sociedades do que os valores dos homens. Os homens têm um senso de competitividade muito forte em relação a homens de outras culturas, enquanto as mulheres sentem carinho e afeição por suas semelhantes, mesmo que de culturas diferentes. Mulheres, em países de maior feminilidade, compartilham os mesmos valores com os homens, de modéstia e carinho. Em países de maior masculinidade, as mulheres mostram-se um pouco mais agressivas e competitivas, mas não tanto quanto os homens, apresentando diferença entre os valores femininos e masculinos (HOFSTEDE, 1994).

Culturas de maior masculinidade tendem a dar mais importância aos resultados da negociação e à competitividade do processo, enquanto culturas de maior feminilidade dão grande importância às relações de confiança entre as partes, tendendo a buscar resultados mutuamente satisfatórios. Nestas culturas, as relações entre os negociadores tendem a ser mais pessoais (SOBRAL; CARVALHAL; ALMEIDA, 2008). Esta dimensão compreende o nível de distanciamento entre as pessoas devido ao seu gênero sexual. Nas culturas mais femininas não existe diferenciação entre gêneros, e homens e mulheres são tratados de maneira igualitária, inclusive no âmbito empresarial (MOTTA, 1997).

A aversão à incerteza é a dimensão que contempla a tolerância da sociedade com a incerteza e a ambiguidade. Certas culturas preparam seus membros para se sentirem confortáveis ou desconfortáveis em situações não estruturadas e não programadas, ou seja, situações desconhecidas, surpreendentes e diferentes do usual. Culturas com maior aversão à incerteza tentam minimizar a possibilidade de ocorrência de tais situações, apelando a normas e regras estritas, medidas de segurança, além de crenças filosóficas e religiosas que pregam a verdade absoluta. Já culturas com menor aversão à incerteza são mais tolerantes a opiniões diferentes e tentam aterem-se ao menor número de regras possível. Suas crenças filosóficas e religiosas são mais relativistas e permitem mais de uma interpretação ou 
verdade (HOFSTEDE, 1994). Negociadores provenientes de culturas com mais aversão ao risco tendem a apreciar negociações baseadas em fatos, e não apenas em suposições, além de sempre solicitar que os termos negociados sejam formalizados em documentos escritos. Tais negociadores, geralmente, levam mais tempo para tomar decisões, uma vez que sempre buscam confirmar todas as informações recebidas. Por outro lado, negociadores de culturas com menos aversão à incerteza são capazes de se adaptar mais rapidamente a situações não previstas e propor soluções mais inovadoras e arriscadas (SOBRAL; CARVALHAL; ALMEIDA, 2008).

Orientação de longo prazo versus orientação de curto prazo é a dimensão que mostra quais as virtudes que determinada sociedade busca. Culturas com orientação de longo prazo buscam a promoção das virtudes voltadas para futuras recompensas. Mostram uma capacidade de adaptar suas tradições às novas condições, uma forte propensão a poupar e investir, frugalidade e perseverança na obtenção de resultados (HOFSTEDE, 1994). Culturas com orientação de curto prazo defendem a promoção de virtudes relacionadas com o passado e o presente. Apresentam grande respeito pelas tradições, pouca propensão a poupar para o futuro e foco na obtenção de resultados rápidos. Em culturas com orientação de longo prazo, é comum que os executivos busquem investir na construção de uma posição de mercado forte, em detrimento de resultados imediatos (HOFSTEDE; HOFSTEDE; MINKOV, 2010).

Por fim, a dimensão indulgência versus restrição, a qual mede a capacidade de uma cultura de satisfazer as necessidades imediatas e os desejos dos seus membros (HOFSTEDE, 2013). Uma sociedade indulgente é aquela que permite a gratificação de seus membros, que devem aproveitar a vida e se divertir. Uma sociedade restritiva suprime a gratificação das necessidades e desejos e os regula por meio de normas sociais estritas. Executivos de sociedades indulgentes costumam exalar alegria e otimismo, mesmo estando preocupados com algo (ex.: a forma como a negociação está acontecendo). Executivos de culturas mais restritas assumem que uma expressão severa seja sinal de seriedade, entendendo sorrisos como falta de interesse dos outros negociadores (HOFSTEDE; HOFSTEDE; MINKOV, 2010).

Sobral, Carvalhal e Almeida (2008) ainda propõem outros dois fatores (ou dimensões) culturais que consideram relevantes para as negociações internacionais: a 
orientação de tempo e a orientação de espaço. A orientação de tempo afeta as negociações na medida em que negociadores provenientes de culturas com sistema de tempo policrônico, ou seja, que aceita que várias coisas aconteçam ao mesmo tempo, são mais flexíveis durante o processo de negociação e menos rígidos em seguir uma agenda. São capazes de falar e negociar sobre diversas coisas ao mesmo tempo, além de se distraírem mais facilmente. Negociadores provenientes de culturas com sistema de tempo monocrônico, ou seja, nas quais o tempo é percebido de forma linear e uma coisa deve acontecer, necessariamente, após a outra, tendem a negociar cada tópico da agenda de maneira individual e sequencial. Por sua vez, a orientação de espaço afeta as negociações, uma vez que negociadores de culturas territoriais tentam manter certa distância das outras partes ao se comunicarem durante o processo de negociação. Já os negociadores de culturas não territoriais preferem manter mais proximidade das outras partes, sendo comum até o contato corporal (físico) durante a negociação (MUNTER, 1993 apud SOBRAL; CARVALHAL; ALMEIDA, 2008).

Outra característica que pode influenciar a negociação internacional é o contexto cultural, representado através das culturas de alto contexto versus culturas de baixo contexto. As culturas de alto contexto são aquelas em que a comunicação exige que sejam explícitas muitas informações adicionais, como o passado dos indivíduos, seus valores e posição na sociedade, pois as mensagens não podem ser compreendidas sem o seu contexto. Culturas de alto contexto são caracterizadas pela forma expressiva em que a mensagem é entregue, por exemplo, utilizando comportamento não verbal (expressões faciais, gestos e linguagem corporal). Quando a comunicação envolve indivíduos de diferentes contextos culturais, pode haver dificuldade de compreensão, pois a complexidade do comportamento não verbal dificilmente será entendida por aqueles oriundos de culturas de baixo contexto (HALL, 1989).

O contexto cultural pode afetar uma negociação internacional, porque os negociadores provenientes de culturas de alto contexto sempre buscam estabelecer relações pessoais com a outra parte, considerando o relacionamento e a confiança como essenciais em qualquer tipo de negócio (SIMINTIRAS; THOMAS, 1998; ROSS; ROBERTSON, 2007). Devido a isso, negociações e acordos podem tomar mais tempo, pois o contexto social é muito mais importante do que qualquer acordo escrito ou contrato legal. Nas culturas de Revista Eletrônica de Estratégia \& Negócios, Florianópolis, v.9, n.1, jan./abr. 2016. 
baixo contexto, as mensagens são explícitas e as relações sociais não são consideradas tão importantes, fazendo com que os detalhes da negociação sejam analisados rapidamente (SIMINTIRAS; THOMAS, 1998).

Lin e Miller (2003) propõem mais duas dimensões que afetam, de forma indireta, as relações entre pessoas de diferentes nacionalidades e, portanto, as negociações internacionais. A dimensão ingroup-outgroup refere-se à interação dos indivíduos com membros pertencentes ou não ao seu grupo. Esta dimensão está intrinsecamente ligada à dimensão individualismo versus coletivismo proposta por Hofstede (1994) (LIN; MILLER, 2003). Como membros de culturas coletivistas são mais conectados a seus grupos, sua comunicação e interação com pessoas que pertencem a esses grupos tende a ser diferente, se comparada com aqueles que não pertencem. Dessa forma, tais indivíduos são mais propensos a ter abordagens diferentes durante a negociação, quando enfrentam um amigo ou um estranho (LIN; MILLER, 2003).

No que diz respeito à segunda dimensão, existem basicamente duas formas de exercer autoridade. A primeira é baseada na institucionalização do poder dos indivíduos, que é construída de modo vertical (de cima para baixo) e é executada de maneira racional, impessoal e burocrática. Negociadores que exercem sua autoridade dessa maneira buscam impor-se perante a outra parte, e consideram essa atitude necessária para facilitar o processo decisório. A segunda é construída através da legitimação e reconhecimento dos subordinados, e é executada de maneira tradicional e paternal. Neste caso, os negociadores preferem usar sua autoridade não para dominar, mas para fomentar a confiança e diminuir as incertezas. Estes negociadores acreditam que, na realidade, o uso de poder coercivo diminui o controle nas negociações (LIN; MILLER, 2003). Isto sugere comportamentos voltados à construção de relacionamentos entre os parceiros, mesmo que tenham objetivos individuais, o que pode não somente explicar um melhor desempenho para as partes (MATANDA; FREEMAN, 2009), como a própria intenção das empresas envolvidas (DOSOGLUGUNER, 2001).

\subsection{CARACTERÍSTICAS CULTURAIS BRASILEIRAS PERCEBIDAS NAS NEGOCIAÇÕES}

Como dito anteriormente, a cultura brasileira é proveniente de três matrizes (indígena, portuguesa e africana). Além disso, a influência dos imigrantes italianos, alemães, Revista Eletrônica de Estratégia \& Negócios, Florianópolis, v.9, n.1, jan./abr. 2016. 
árabes, japoneses, entre tantos outros, faz com que cada região do Brasil pareça ter sua própria cultura, expressa na culinária, nas músicas e na maneira de vestir de cada local (MOTTA, 1997). Entretanto, apesar da pluralidade de comportamentos e símbolos, o núcleo central da cultura brasileira é o mesmo, apresentando relativa homogeneidade (FREITAS, 1997). Dessa forma, é possível identificar uma série de características culturais, ou fragmentos culturais comuns a todas as regiões, e que levam em conta a diversidade existente no Brasil (MORELLI et al., 2002).

Para Morelli et al. (2002, p. 8), "junto à forte mistura cultural realizada no curso de sua história, a diversidade representa um princípio organizador, o mecanismo através do qual a identidade cultural brasileira se produz". Ou seja, a evidente diversidade cultural presente no Brasil é justamente o fator mais marcante e específico da cultura brasileira. Inclusive, a pluralidade presente na cultura brasileira permite inúmeras possibilidades de classificação na sociedade. É possível, por exemplo, classificar uma pessoa por sua cor de pele, pelo montante de dinheiro que possui, pelo nome de sua família ou pelo lugar onde mora. Tais classificações são, na verdade, uma forma de preconceito e de discriminação, pois impõem diferenças e apontam quem é superior e quem é inferior na sociedade (FREITAS, 1997).

Ao conduzir seus estudos sobre as dimensões culturais no Brasil, Hofstede (2013) pôde identificar que o país tem uma cultura hierárquica, coletivista, equilibrada entre os valores femininos e masculinos, com aversão ao risco e às incertezas e com orientação de longo prazo. A dimensão indulgência versus restrição, por ser muito recente, ainda não foi analisada no Brasil. No que tange à dimensão distância de poder, que expressa a atitude de determinada cultura com as desigualdades, o Brasil obteve uma pontuação de 69 sobre 100, refletindo que a sociedade brasileira acredita que a hierarquia deve ser respeitada e as desigualdades entre as pessoas são aceitáveis. Segundo observações do autor, no Brasil, nas empresas há sempre somente um chefe que assume a responsabilidade completa, delegando tarefas, e seus subordinados. É comum que as pessoas carreguem e exaltem símbolos de status e de poder, a fim de indicar sua posição social e demandar respeito.

O fato de a sociedade brasileira apresentar uma distância de poder tão grande é herança do passado escravocrata do país. O senhor do engenho era responsável pela 
administração de suas terras, família e escravos, e era absoluto em suas decisões. A grande distância social que existia entre senhores e escravos explica a indiferença que as classes dominantes demonstram pelos mais pobres, ao contrário do que acontece em muitos outros países, onde todos são considerados iguais, independente de sua condição social (MOTTA, 1997). Em relação às instituições, a concentração de poder e a hierarquia levam a outra característica do povo brasileiro: a postura de expectador, consequência da baixa consciência crítica do povo, bem como de sua pouca capacidade de realização por autodeterminação e de sua tendência de transferir a responsabilidade das dificuldades para as lideranças. Desse modo, mesmo quando o brasileiro tem liberdade para atuar e tomar suas próprias decisões, ele não é capaz de fazê-lo, seja porque não sabe ou porque não tem vontade própria, voltando a direcionar sua conduta às exigências de sua autoridade (PRATES; BARROS, 1997).

Ao analisar a dimensão individualismo versus coletivismo, o grau de interdependência entre os membros de determinada sociedade, Hofstede (2013) aponta que o Brasil demonstra a importância da integração das pessoas em grupos fortes e coesos, especialmente representados pela família. Quanto às relações de trabalho, é importante construir relações duradouras e de confiança. Por isso, uma reunião geralmente começa com conversas em geral, a fim de fazer com que as partes se conheçam melhor antes de fazer negócios. Além disso, de acordo com Motta (1997), esta dimensão explica o fato de que, na sociedade brasileira, o nepotismo é uma tendência muito forte. É comum haver o favorecimento de parentes ou amigos próximos em detrimento de pessoas mais qualificadas na designação de cargos nas organizações e no mercado de trabalho em geral. O senso coletivista gera a expectativa de que os membros mais velhos e poderosos de uma família possam ajudar os mais novos a serem contratados para um emprego em suas próprias empresas.

Por ser uma cultura tão coletivista, o personalismo é importante para os brasileiros. O personalismo é "o magnetismo exercido pela pessoa, por meio de seu discurso ou de seu poder de ligações (relações com outras pessoas), e não por sua especialização" (PRATES; BARROS, 1997, p. 60). Os grupos sociais (amigos, família e colegas de trabalho) são meios utilizados pelos indivíduos para resolver seus problemas e obter vantagens. "O indivíduo isolado e sem relações é considerado como altamente negativo, um ser marginalizado em Revista Eletrônica de Estratégia \& Negócios, Florianópolis, v.9, n.1, jan./abr. 2016. 
relação aos outros membros da comunidade" (PRATES; BARROS, 1997, p. 60). Em acréscimo, a combinação de duas características mencionadas anteriormente, a forte hierarquia e o personalismo, têm como síntese o paternalismo, a percepção de que o patriarca é detentor de todo o poder e que os demais membros só podem pedir e obedecer. O paternalismo gera dupla dependência, pois proporciona maior grau de segurança para o grupo e, por outro lado, dá menor grau de liberdade e autonomia para seus membros (PRATES; BARROS, 1997).

Na dimensão masculinidade versus feminilidade, Hofstede (2013) evidenciou que a principal questão relacionada a esta dimensão é o que motiva as pessoas? Uma reflexão sobre querer ser o melhor (inclinação à masculinidade) ou gostar do que se faz (inclinação à feminilidade). Os resultados indicaram que os valores masculinos, como sucesso, dinheiro e bens materiais são valorizados tanto quanto os valores femininos, como a preocupação com os outros, relações interpessoais e qualidade de vida (SOBRAL; CARVALHAL; ALMEIDA, 2008). Na dimensão aversão à incerteza, o Brasil obteve resultado similar ao da maioria dos países latino-americanos. A sociedade brasileira mostra forte necessidade de leis, sistemas jurídicos elaborados, regras e burocracia (HOFSTEDE, 2013). Todavia, é importante salientar que os indivíduos tendem a desobedecer a estas leis ou regras, muitas vezes.

Ao analisar a dimensão orientação de longo prazo versus orientação de curto prazo, Hofstede (2013) verificou que o país está entre as sociedades orientadas ao longo prazo. Os brasileiros tendem a procurar alternativas para fazer o que, em outros olhos, poderia ser considerado como impossível. Como os asiáticos, os brasileiros aceitam mais do que uma verdade, e facilmente aceitam a mudança como parte de sua vida. No que diz respeito à orientação de tempo, orientação de espaço e contexto cultural, o Brasil também é muito parecido com outros países da América Latina, e opera em um sistema de tempo policrônico. Os brasileiros são pouco rigorosos em manter suas programações diárias, são capazes de dividir sua atenção com vários assuntos ao mesmo tempo e não estão preocupados com a velocidade dos processos (SOBRAL; CARVALHAL; ALMEIDA, 2008). Esta gestão flexível do tempo tem como consequência a impontualidade. É aceitável estar apenas alguns minutos atrasado para qualquer tipo de encontro no Brasil (TURNER; KLEINER, 2001).

Além disso, o Brasil é caracterizado pela proximidade espacial entre as pessoas. Há pouca preocupação com a defesa do espaço territorial individual e é normal que as pessoas 
se toquem durante a comunicação (SOBRAL; CARVALHAL; ALMEIDA, 2008; WALTER; FREGA, 2015). Aliás, Freitas (1997) afirma que os brasileiros têm grande necessidade de tornar seus relacionamentos mais próximos e afetuosos. Por isso, são conhecidos por seu calor humano no tratamento pessoal. Evitam ao máximo situações violentas e preferem a conciliação e a amizade. Isto fica claro pela forma como os brasileiros cumprimentam uns aos outros. Beijos e abraços apertados são comuns, mesmo quando os indivíduos estão sendo apresentados pela primeira vez.

A cultura brasileira é uma cultura de alto contexto, o que significa que a comunicação não é explícita e direta, mas interpretada com base nas expressões não verbais e no contexto da conversa (SOBRAL; CARVALHAL; ALMEIDA, 2008). Aliás, Freitas (1997) expõe outros dois traços culturais que considera predominantes na cultura brasileira, principalmente no que diz respeito à cultura organizacional. São eles: a malandragem (ou jeitinho) e o sensualismo. A malandragem, no Brasil, é sinônimo de esperteza. Malandro é o indivíduo que dificilmente é enganado, que é flexível e consegue se adaptar às mais diversas situações. O malandro, por ser dinâmico e ativo, sempre propõe soluções inovadoras e criativas. Já o famoso jeitinho brasileiro é o intermédio entre o certo e o errado (FREITAS, 1997). Segundo Barbosa (1992, p. 32), o jeitinho brasileiro "é sempre uma forma "especial" de se resolver algum problema ou situação difícil ou proibida; ou uma solução criativa para alguma emergência". É importante ressaltar que a malandragem, neste contexto, não é aquela necessariamente de caráter pejorativo ou até mesmo criminal, mas a que é valorizada e incentivada no Brasil (FREITAS, 1997), e que é utilizada indistintamente por todos os segmentos sociais brasileiros (BARBOSA, 1992). O sensualismo, por sua vez, é herança da época da colonização portuguesa, quando as negras, trazidas da África, geraram um ambiente de libertinagem sexual no Brasil colônia. Atualmente, é possível perceber a presença da cultura sensual nas festas típicas brasileiras, como o Carnaval, e até mesmo na maneira de vestir e de falar. Frequentemente, o brasileiro se utiliza do sensualismo em suas relações como uma maneira de obter o que deseja mais facilmente (FREITAS, 1997).

Caldas (1997) aponta outras características comuns a quase todos os brasileiros, o complexo de inferioridade e a fixação pela figura do estrangeiro. Os brasileiros têm a percepção de que os produtos culturais e de consumo importados são melhores do que aqueles disponíveis no mercado nacional; de que nada no Brasil presta; e de que qualquer Revista Eletrônica de Estratégia \& Negócios, Florianópolis, v.9, n.1, jan./abr. 2016. 
coisa de valor tem de vir de fora. A causa da mentalidade brasileira orientada para o estrangeiro é a sua matriz histórica. Quando os europeus chegaram ao Brasil, não tentaram adaptar-se à cultura local, mas implantaram um modelo de colonização exploratória e extrativista. O Brasil foi formado, então, como um país sem identidade e caráter próprio, o que reflete na adoração que o brasileiro tem pelo que é estrangeiro e pela falta de valor que dá ao nacional.

Um último aspecto cultural a ser mencionado é a religiosidade do povo brasileiro. Dourado Filho e Sebben (2010) afirmam que o brasileiro é fortemente influenciado por suas crenças, e conta com a ajuda divina até mesmo no ambiente organizacional. A expressão se Deus quiser! faz parte do cotidiano. No entanto, apesar de a maioria dos brasileiros ser de católicos, muitos frequentam também terreiros de candomblé e centros espíritas, além de outros tipos de cultos. Assim sendo, a múltipla religiosidade representa uma forte característica nacional (MORELLI et al., 2002), denotada pelo sincretismo religioso.

\section{MÉTODO DE PESQUISA}

A fim de atender ao objetivo do estudo, optou-se pela utilização do método de pesquisa qualitativa de caráter exploratório (HENNINK; HUTTER; BAILEY, 2011; REMLER; VAN RYZIN, 2011). Esta escolha justifica-se por ser o método mais adequado para o estudo de fenômenos sociais, uma vez que é capaz de dar conta da natureza complexa e idiográfica (não repetível), e holística (que exige a visão da totalidade) de tais fenômenos (SCOTT; GARNER, 2013; MILES; HUBERMAN; SALDAÑA, 2014).

Para tanto, foram realizadas entrevistas individuais em profundidade que, por sua natureza interativa, permitiram tratar de um tema complexo, que dificilmente poderia ser investigados adequadamente através de um questionário estruturado (HENNINK; HUTTER; BAILEY, 2011). A abordagem utilizada para a condução das entrevistas foi a semiestruturada, já que se utilizou um roteiro básico de questões para a coleta de dados (RIBEIRO; MILAN, 2004; KVALE; BRINKMAN, 2009; KING; HORROCKS, 2010). O roteiro apresentou, inicialmente, questões introdutórias, cuja finalidade foi apresentar o tópico geral da discussão e motivar o respondente a refletir sobre suas experiências relacionadas ao tema em estudo. $\mathrm{Na}$ sequência foram elaboradas questões de transição, que direcionaram a entrevista para as questões-chave, centrais do estudo, e que demandaram maior atenção e análise. A Revista Eletrônica de Estratégia \& Negócios, Florianópolis, v.9, n.1, jan./abr. 2016. 
entrevista foi encerrada com o entrevistador fazendo um resumo, de dois a três minutos, das principais ideias mencionadas na discussão, questionando o entrevistado se o resumo foi adequado e abrindo espaço para o mesmo acrescentar algum aspecto ou comentário. Vale destacar que as entrevistas foram realizadas pessoalmente ou por videoconferência (no caso dos respondentes residentes no exterior).

A fim de tratar o tema sob os pontos de vista acadêmico e prático, os participantes do estudo foram selecionados por conveniência e divididos em dois grupos. No intuito de entender como o tema é tratado pelos acadêmicos e pelos estudiosos da área, o primeiro grupo foi composto por quatro experts nas áreas de cultura e de negociação internacional, com conhecimento no que se refere às temáticas do estudo, devido à sua formação e atuação acadêmica. Para buscar o entendimento de como os negociadores observam, na prática, a influência dos aspectos culturais na sua atividade profissional, o segundo grupo foi composto por oito executivos de diversas nacionalidades, que participam ativamente de negociações com brasileiros há, pelo menos, dois anos. Cabe ressaltar que a busca de percepções de indivíduos com larga experiência em contextos de pesquisa, neste caso, profissionais e experts da área, é algo visto como justificável e relevante (HENNINK; HUTTER; BAILEY, 2011).

No início de cada entrevista, além de explicitar o objetivo da pesquisa, foram coletados dados pessoais de cada um dos entrevistados, a fim de caracterizar seus perfis. Para tanto, foram questionadas a idade, nacionalidade, formação acadêmica e profissão dos entrevistados. No caso dos experts, todos são brasileiros com idades entre 32 e 48 anos. Dois deles são negociadores profissionais, com ampla carteira de clientes internacionais e experiência de mais de 15 anos no ramo. Os outros dois são professores universitários, com conhecimento acadêmico extenso sobre os assuntos abordados. Os negociadores estrangeiros, coincidentemente, também têm idades entre 32 e 48 anos, são provenientes de cinco diferentes continentes e todos atuam em cargos relacionados à negociação de suas empresas com companhias brasileiras. As entrevistas com os experts tiveram duração média de 69 minutos, enquanto com os negociadores, de 32 minutos.

Para o tratamento, análise e interpretação dos dados, a técnica utilizada foi a análise de conteúdo (BARDIN, 2004; SCHREIER, 2012; KRIPPENDORFF, 2013). A fim de 
garantir maior clareza e fidedignidade no processo de análise e interpretação dos dados coletados, os mesmos foram categorizadas conforme recomendações encontradas na literatura (BARDIN, 2004; BERNARD; RYAN, 2010; REMLER; VAN RYZIN, 2011; MILES; HUBERMAN; SALDAÑA, 2014), categorias estas relativas aos aspectos culturais que influenciam na negociação internacional e às características culturais brasileiras.

\section{APRESENTAÇÃO DOS RESULTADOS}

\subsection{ASPECTOS CULTURAIS QUE INFLUENCIAM NA NEGOCIAÇÃO INTERNACIONAL}

As entrevistas com os experts iniciaram com uma pergunta introdutória, a fim de identificar se os mesmos acreditavam que a cultura de determinado país pode afetar a negociação internacional. Todos os entrevistados afirmaram acreditar que a cultura é um fator determinante neste tipo de negociação, além de atestarem que o respeito e a compreensão mútua são essenciais para o sucesso de qualquer negócio que envolva pessoas de diferentes nacionalidades e valores culturais.

Em seguida, os experts foram questionados sobre quais características culturais podem ter influência na negociação internacional. A distância de poder foi mencionada por todos os entrevistados que, de forma geral, acreditam que as relações de poder e hierarquia variam de uma cultura para outra, e que isso deve ser observado pelos negociadores que desejam obter êxito no ambiente internacional. Eles mencionam que até o número de pessoas negociando pode ter influência no processo de negociação, e que é necessário, além do entendimento dos níveis hierárquicos de cada cultura e/ou das empresas envolvidas (e de origens diferentes), que o negociador seja capaz de identificar quem são as pessoas tomadoras de decisão, que não necessariamente são aquelas que estão no topo da pirâmide hierárquica.

Grande parte dos entrevistados (dos experts) apontou que o fato de uma cultura ser mais individualista ou coletivista pode ter impacto na negociação. Eles acreditam que esta característica tem especial relação com a maneira como as decisões são tomadas, tendo em vista que o individualismo de determinada cultura pode determinar, ao negociador, mais autonomia na tomada de decisões, enquanto em culturas mais coletivistas é geralmente necessário um aval de todo o grupo. Além disso, os experts afirmaram que culturas mais 
coletivistas tendem a dar mais valor às relações pessoais e que, de outro modo, culturas individualistas prezam pelo resultado e não acreditam que o relacionamento seja um aspecto tão importante ou determinante nos negócios.

Em relação aos contratos e às regras, os experts comentaram que eles são necessários em qualquer negócio, mas que certas culturas tendem a exigi-los mais do que outras. Eles creem que a formalização do negócio é necessária para garantir sua solidez, mas que o excesso de burocracia pode vir a ser um problema, indicando falta de preparo profissional dos negociadores e das empresas estrangeiras. Além disso, todos os entrevistados apontaram que a burocracia é maior nos países menos desenvolvidos, e que os grandes negócios começam, normalmente, de maneira muito informal.

Quando questionados sobre o impacto da orientação de curto ou de longo prazo na negociação, os entrevistados informaram que este é um aspecto cultural que gera muito conflito no ambiente internacional, uma vez que, em alguns países, é mais difícil prever acontecimentos futuros (ex.: decisões políticas). Por isso, os negociadores não estão dispostos a fazer planos em longo prazo. Eles acreditam que é necessário um equilíbrio entre as duas orientações e que, se não houver consenso entre as partes, não é possível fazer negócios.

Outro aspecto que pode ter influência na negociação internacional, e que foi apontada pelos entrevistados, é a percepção do tempo. De acordo com os experts, certas culturas como, por exemplo, a norte-americana, presume que o tempo é valioso e, desta forma, a negociação deve ser focada nos seus objetivos mais diretos, deixando os relacionamentos para o segundo plano. Já em outras culturas, como é o caso da japonesa, há a percepção de que o relacionamento é parte essencial do negócio, e que é necessário tempo para o amadurecimento das relações. Assim sendo, as negociações podem tomar muito mais tempo no último caso. Além disso, os entrevistados mencionam que algumas culturas são extremamente rígidas no cumprimento de horários e de compromissos (ex.: a cultura inglesa), enquanto outras podem ser mais flexíveis (ex.: a cultura brasileira). Eles também declinaram que os assuntos governamentais tendem a ser mais formais em qualquer cultura e afirmam, ainda, que é necessário que o negociador se organize 
previamente à negociação e tenha uma pauta para as reuniões, sendo mais objetivo e, consequentemente, aumente suas chances de sucesso.

Quando convidados a fazer suas considerações finais sobre o impacto da cultura na negociação internacional, os experts apontaram o fato de que, atualmente, devido ao acesso facilitado à informação, a negociação internacional está mais profissional do que nunca, uma vez que os negociadores estão lendo mais e se informando mais sobre as demais culturas com as quais vão negociar, o que os inibe de cometer gafes culturais. Eles ainda mencionam que, no ambiente internacional, é comum que as pessoas se desprendam da sua cultura de origem e que atuem de forma mais neutra e natural. Finalmente, os entrevistados atentam ao fato de que é necessário cuidado ao estereotipar as culturas em relação aos aspectos intrínsecos à negociação, uma vez que os traços culturais predominantes de cada cultura podem ser suavizados devido à alta exposição do negociador ao ambiente multicultural.

\subsection{CARACTERÍSTICAS CULTURAIS BRASILEIRAS}

Ao serem questionados sobre as principais características culturais brasileiras, tanto experts quanto negociadores têm opiniões convergentes ao indicar que existe uma grande distância de poder no Brasil. Os experts afirmam que, apesar do clima amistoso que existe nas organizações brasileiras, a relação hierárquica é muito forte. Esta é uma característica negativa na medida em que os funcionários que estão nos níveis mais baixos da hierarquia deixam de dar suas contribuições ao negócio. Eles apontaram que há predominância de gestores centralizadores e autoritários no Brasil. Ademais, entendem que é comum que, nas organizações brasileiras, as pessoas dos escalões mais baixos não sejam capazes de executar suas tarefas sem supervisão, adotando uma postura de expectadores de seus gestores, sendo mais passivas.

Os negociadores entrevistados, em especial, posicionaram-se no sentido de que as empresas mais bem sucedidas são aquelas que têm uma estrutura hierárquica mais plana, e que este não é o caso brasileiro, principalmente no que diz respeito às grandes empresas. Eles apontaram que uma grande distância de poder é prejudicial ao negócio, pois inibe as pessoas de serem honestas e de compartilharem suas ideias e opiniões, e que o excesso de hierarquia pode tornar os negócios mais lentos. 
O nepotismo, ou o favorecimento de parentes e amigos na designação de cargos foi outra característica apontada como prática presente na cultura brasileira por três dos quatro experts entrevistados. No entanto, boa parte deles acredita que tal prática não seja necessariamente negativa, desde que a pessoa contratada cumpra os requisitos necessários. Segundo estes entrevistados, a confiança é um elemento essencial em qualquer negócio, e não é possível mudar o comportamento das pessoas. Por isso, muitas vezes, é preferível contratar uma pessoa em quem se tem confiança do que uma pessoa com melhor qualificação técnica, porém, não confiável. A opinião dos negociadores é convergente. A maioria deles aponta que o nepotismo está presente em todos os países, não apenas no Brasil, não o vendo como uma prática obrigatoriamente negativa.

De acordo com um dos experts, o brasileiro tem um estilo de negociação integrativo, buscando entender sempre a outra parte, e a chegar a um consenso para que a negociação tenha resultado positivo para todos e que possa gerar, no futuro, um relacionamento estreito, duradouro. Ele menciona, ainda, que esta é uma forma equilibrada de negociação, e que difere da forma como as culturas que têm os valores masculinos mais fortes negociam. Em acréscimo, os negociadores mencionaram que, diferente do que ocorre em outros países, as negociações no Brasil não giram apenas em torno de números e de resultados. Segundo eles, a confiança e o bom relacionamento são vitais ao fazer negócios com os brasileiros, que são flexíveis e não parecem ser tão ligados ao status, a bens materiais e ao consumismo.

Em contrapartida, entre os experts, há um consenso de que a burocracia é muito forte no Brasil. Eles afirmaram que, ao negociar, o brasileiro não tem muita confiança na outra parte e, por isso, busca mecanismos para aumentar sua segurança, como contratos e a presença de advogados. Tal evidência, de certa forma, contradiz as opiniões anteriormente apresentadas. Isso gera custos e uma demanda de tempo desnecessária, uma vez que não é possível se precaver de todos os riscos ou incertezas em uma negociação. Para os entrevistados, o Brasil passou por períodos históricos de inflação muito alta, e esta pode ser a principal razão da alta aversão à incerteza do brasileiro. Eles entendem que isso é uma característica negativa no contexto da negociação internacional, pois a burocracia demasiada, apesar de ter sido criada com o objetivo de facilitar os negócios, acaba 
prejudicando-os. Um exemplo é a legislação brasileiras, que se sobrepõe, e os impostos em efeito cascata.

Conforme todos os negociadores entrevistados, a burocracia brasileira afeta negativamente seus negócios com o Brasil. Um deles, inclusive, afirmou que tempo é dinheiro, e que o excesso de burocracia é prejudicial ao negócio. Os entrevistados acreditam que, de forma geral, os sistemas brasileiros não são bem estruturados e regulamentados e que, em outros países, não há a necessidade de leis e regras tão estritas, pois a tendência é que elas mudem constantemente, o que não ocorre de maneira similar no Brasil. Eles complementaram tal ideia, informando que a desburocratização gera aumento de competição, o que ocasiona melhora nas companhias (organizações), e que isso pode ser percebido em grandes potências mundiais, tais como os Estados Unidos e países da Europa, mas não no Brasil.

Apesar da grande necessidade de leis e regras, experts e negociadores percebem que o brasileiro apresenta tendência a desobedecê-las. De acordo com os experts, os contratos são, muitas vezes, apenas mera formalidade, e são esquecidos após serem firmados. Isso ocorre também, de certa forma, com as leis brasileiras. Eles acreditam que tal comportamento seja um reflexo do fato de que tais leis são criadas sem levar em consideração a real necessidade ou realidade da sociedade. Para os negociadores, o brasileiro nem sempre segue os contratos de maneira estrita, e as muitas regras e regulamentos do país nem sempre são obedecidos integralmente.

Outra característica apontada pelos experts é a tendência do brasileiro de fazer planos para o curto prazo. Isto ocorre principalmente nas esferas públicas, que tendem a executar ações sem um planejamento mais detalhado e efetivo. Eles mencionaram, ainda, o período inflacionário brasileiro (década de 80 e início da de 90), e afirmam acreditar que este seja o principal fator gerador da necessidade dos brasileiros de perceber resultados no curto prazo. Um dos entrevistados, inclusive, comentou que esta orientação em curto prazo gera afoites, o que pode levar o negociador brasileiro a ignorar etapas, informações ou mecanismos essenciais no processo de negociação internacional, repercutindo no não fechamento de negócios ou em problemas ou conflitos evitáveis no futuro. 
A orientação de curto prazo do brasileiro também foi mencionada por grande parte dos negociadores entrevistados. Para eles, o brasileiro sempre procura tirar o máximo de proveito possível em um curto período de tempo. Eles acreditam que isso seja negativo, uma vez que melhores resultados são alcançados a partir de planos de longo prazo, e o mercado global pode exigir planos de até dez ou vinte anos, no que se refere a investimentos mais robustos e aos devidos retornos esperados (ex.: investimentos em infraestrutura no contexto do modal ferroviário). Os negociadores entrevistados colocaram, ainda, que sem estes planos é possível atingir o resultado final esperado, mas isso pode demorar muito mais tempo.

Quando questionados sobre a orientação de tempo do brasileiro, os experts afirmam que a cultura brasileira é caracterizada por uma visão policrônica da passagem do tempo. Segundo eles, o negociador brasileiro tende a falar sobre várias coisas ao mesmo tempo, e não é incomum que ele fale sobre amenidades durante a negociação internacional, ou seja, há perda de foco no processo negocial. Os entrevistados acreditam que isso pode ser prejudicial à negociação intercultural, uma vez que nem todas as culturas estão acostumadas e encaram tal característica com naturalidade ou, até mesmo, como algo aceitável.

Os negociadores entrevistados também comentaram que, geralmente, o brasileiro não se apega aos compromissos agendados, e que é muito flexível quando as circunstâncias mudam. Parte deles acredita que isso é positivo, já que mudanças de planos são comuns e é necessário adaptar-se a elas. Todavia, um dos negociadores entrevistados apontou que a falta de preocupação do brasileiro com o tempo e com suas programações é prejudicial para os negócios, seja na sua condução, seja em relação aos seus resultados.

A impontualidade também foi destacada pelos experts como uma característica cultural do brasileiro. De acordo com eles, ela é negativa quando leva ao não cumprimento dos prazos definidos, pois pode minar a confiança entre as partes negociantes. Por outro lado, a impontualidade é positiva para os negócios quando é sinônimo de flexibilidade, já que a falta de cumprimento de horários pode ser causada por imprevistos, e isso não deve ser um empecilho às negociações internacionais. Eles afirmam que o negociador internacional deve ser pontual, mesmo que isso implique em sair para seus compromissos 
com bastante antecedência, mas que o brasileiro não tem este costume. Para um dos entrevistados, os estrangeiros têm uma visão muito forte de que o brasileiro é impontual, desorganizado e não cumpre com seus prazos e promessas, o que não seria uma verdade absoluta. Entretanto, todos os negociadores entrevistados concordam que a impontualidade é uma característica do povo brasileiro, e veem isto de maneira muito negativa. Segundo eles, o tempo é muito importante nos negócios, e ser pontual é um sinal de respeito e profissionalismo.

Outra característica cultural brasileira apontada pelos experts é a proximidade espacial e a afetividade. De acordo com um dos entrevistados, atitudes que demonstram afeto podem ser vistas como invasivas por negociadores de outras culturas, mas ele acredita que isso pode apenas causar constrangimento, desconforto, não impactando negativamente na negociação internacional de forma definitiva. Para outro, esta é uma característica positiva do povo brasileiro, pois abraços e beijos demonstram confiança e permitem que a negociação seja levada para um nível mais elevado. Os entrevistados entendem que, de forma geral, o estrangeiro não tem uma percepção efetivamente negativa sobre isto, mas que é preciso ter respeito com as culturas que não veem a proximidade espacial como algo positivo. Parte dos negociadores entrevistados acredita que tal característica pode afetar negativamente os negócios. Nem todas as pessoas gostam de toques, beijos e abraços, e que tal comportamento pode ser considerado falta de profissionalismo aos olhos de executivos estrangeiros, até mesmo um comportamento muito invasivo. Outros veem esta característica como positiva, e afirmam que ela é um reflexo da paixão e do bom relacionamento, típicos dos brasileiros.

O jeitinho brasileiro foi apontado pelos experts como uma característica muito presente na cultura e no dia a dia dos brasileiros. Grande parte deles acredita que o jeitinho represente a flexibilidade do brasileiro e a sua capacidade de se adaptar às regras e às leis, que não são adequadas à sua realidade. Os entrevistados comentaram que ele pode ser visto como algo ilegal ou imoral por aqueles que não compreendem a cultura ou a realidade do país, mas que não é algo realmente negativo para a negociação internacional. Boa parte dos negociadores entrevistados mencionou o jeitinho como uma característica cultural brasileira, e acredita que ele seja positivo para os negócios, pois denota a flexibilidade no trato com as limitações geradas pelas negociações em nível internacional. Um dos Revista Eletrônica de Estratégia \& Negócios, Florianópolis, v.9, n.1, jan./abr. 2016. 
negociadores destacou que não é possível fazer as mesmas exigências com todas as empresas estrangeiras, de diferentes países e que, por isso, as regras têm de ser adaptadas, dependendo da situação.

Outra característica apontada pelos experts é o complexo de inferioridade do brasileiro. De acordo com eles, o brasileiro tende a ser muito crítico com a sua própria cultura e acredita que as culturas dominantes devem ser seguidas e respeitadas, sendo esta uma consequência da maneira como o país foi colonizado e explorado. Os respondentes acreditam que as características negativas do país são supervalorizadas, e que existe uma tendência de o brasileiro aceitar com facilidade os apontamentos da outra parte, e a ceder frente a argumentos de barganha não tão fortes, sendo estas atitudes negativas para os negócios internacionais.

Um dos experts entrevistados comentou que o brasileiro tem fixação pela figura do estrangeiro e pelos produtos e/ou as marcas que vêm do exterior. Segundo ele, isto é negativo para os negócios, pois reflete na percepção de compra dos consumidores brasileiros e, inclusive, dos estrangeiros. Outro expert afirmou que, no passado, os negócios brasileiros passaram por um período de alto protecionismo por parte do governo, e que os produtos disponibilizados no Brasil não eram de muita qualidade, o que pode ter fomentado tal sentimento. Para ele, nos dias hoje, este cenário mudou, e os produtos e/ou serviços que vêm do exterior são parâmetro para os brasileiros melhorarem suas ofertas cada vez mais.

Os negociadores entrevistados também apontaram que o brasileiro percebe os produtos e/ou serviços estrangeiros como de melhor qualidade do que os do país. Um deles comentou que esta não é apenas uma percepção, mas uma realidade. De acordo com ele, o protecionismo do governo brasileiro é tão grande que, ainda hoje, as empresas não têm motivos para competir e tornar seus produtos e/ou serviços melhores. Ele acredita que haja boas empresas no Brasil, mas que a predominância é de empresas medianas.

Os experts apontaram a questão do despreparo como algo muito presente nas negociações internacionais com brasileiros. Eles creem que muitas empresas brasileiras que atuam no ambiente internacional não possuem profissionais preparados e que falem inglês fluentemente, e que nem mesmo as empresas e pessoas que lidam com as áreas internacionais estão atentas às questões culturais. Além disso, um dos experts afirmou que o Revista Eletrônica de Estratégia \& Negócios, Florianópolis, v.9, n.1, jan./abr. 2016. 
brasileiro costuma agir, no ambiente internacional, da mesma maneira com que age em sua própria cultura ou mercado, desconhecendo hábitos e particularidades dos outros países. Ele acredita que o fato de o Brasil ter baixa inserção no comércio internacional seja um reflexo disto. Muitos dos negociadores entrevistados também acreditam que o brasileiro seja despreparado para fazer negócios. De acordo com eles, há muita informalidade e falta de profissionalismo no ambiente empresarial brasileiro.

Finalmente, outra característica abordada apenas pelos negociadores entrevistados é a paixão do povo brasileiro. Para eles, é possível perceber que, no Brasil, as pessoas amam o que fazem, inclusive no ambiente empresarial. Isto pode refletir no desempenho de suas atividades. Eles apontaram, ainda, que os brasileiros são sempre alegres e simpáticos, apesar de todos os problemas que têm de enfrentar, e o alinhamento que existe entre as pessoas e os valores dos negócios é a razão de o brasileiro ser tão apaixonado e orgulhoso por seu trabalho.

Para sintetizar as principais características culturais brasileiras apontadas, tanto por experts quanto pelos negociadores internacionais entrevistados, bem com sua percepção em relação a elas, é apresentada a Figura 1.

Figura 1 - Síntese das características culturais brasileiras

\begin{tabular}{|c|c|c|c|}
\hline \multicolumn{4}{|c|}{ Características Culturais Brasileiras } \\
\hline Características culturais & Descrição & $\begin{array}{l}\text { Percepção } \\
\text { dos experts }\end{array}$ & $\begin{array}{l}\text { Percepção dos } \\
\text { negociadores }\end{array}$ \\
\hline Grande distância de poder & $\begin{array}{l}\text { Relações hierárquicas fortes e } \\
\text { predominância de gestores } \\
\text { centralizadores e autoritários. }\end{array}$ & Negativa & Negativa \\
\hline Nepotismo & $\begin{array}{l}\text { Favorecimento de parentes e amigos } \\
\text { na designação de cargos. }\end{array}$ & $\begin{array}{l}\text { Neutra ou } \\
\text { negativa }\end{array}$ & $\begin{array}{l}\text { Neutra ou } \\
\text { negativa }\end{array}$ \\
\hline Feminilidade & $\begin{array}{l}\text { Busca por relações equilibradas e } \\
\text { integrativas, pouco apreço por status e } \\
\text { bens materiais, ascensão feminina no }\end{array}$ & Positiva & Positiva \\
\hline
\end{tabular}




\begin{tabular}{|c|c|c|c|}
\hline & mercado de trabalho. & & \\
\hline Alta aversão à incerteza & $\begin{array}{l}\text { Falta de confiança na outra parte e } \\
\text { forte presença de leis e burocracia. }\end{array}$ & Negativa & Negativa \\
\hline $\begin{array}{c}\text { Tendência a desobedecer } \\
\text { às leis e às regras }\end{array}$ & $\begin{array}{l}\text { Descumprimento de contratos, regras } \\
\text { e regulamentos. }\end{array}$ & Neutra & Neutra \\
\hline Orientação de curto prazo & $\begin{array}{l}\text { Tendência a fazer planos para o curto } \\
\text { prazo, executar ações sem } \\
\text { planejamento, afoitamento. }\end{array}$ & Negativa & Negativa \\
\hline $\begin{array}{l}\text { Orientação de tempo } \\
\text { policrônica }\end{array}$ & $\begin{array}{l}\text { Tendência a falar sobre várias coisas ao } \\
\text { mesmo tempo, flexibilidade no } \\
\text { cumprimento de compromissos. }\end{array}$ & $\begin{array}{l}\text { Neutro ou } \\
\text { negativa }\end{array}$ & $\begin{array}{l}\text { Positiva ou } \\
\text { negativo }\end{array}$ \\
\hline Impontualidade & $\begin{array}{l}\text { Não cumprimento dos prazos } \\
\text { definidos, horários muito flexíveis. }\end{array}$ & $\begin{array}{c}\text { Positiva ou } \\
\text { negativa }\end{array}$ & Negativa \\
\hline Proximidade espacial & $\begin{array}{l}\text { Tendência a demonstrar afeto através } \\
\text { de toques físicos, beijos e abraços. }\end{array}$ & $\begin{array}{l}\text { Neutra ou } \\
\text { positiva }\end{array}$ & $\begin{array}{l}\text { Positiva ou } \\
\text { negativa }\end{array}$ \\
\hline Jeitinho brasileiro & $\begin{array}{l}\text { Flexibilidade e capacidade de } \\
\text { adaptação às leis e às regras. }\end{array}$ & $\begin{array}{l}\text { Positiva ou } \\
\text { negativa }\end{array}$ & $\begin{array}{l}\text { Positiva ou } \\
\text { negativa }\end{array}$ \\
\hline Complexo de inferioridade & $\begin{array}{l}\text { Tendência de ser muito crítico consigo } \\
\text { mesmo e com sua própria cultura. }\end{array}$ & Negativa & $\begin{array}{l}\text { Neutra ou } \\
\text { negativa }\end{array}$ \\
\hline Despreparo & $\begin{array}{l}\text { Falta de conhecimento, informalidade e } \\
\text { falta de profissionalismo no ambiente } \\
\text { empresarial. }\end{array}$ & Negativa & Negativa \\
\hline Paixão & $\begin{array}{l}\text { Amor pelo que faz, entusiasmo e } \\
\text { simpatia. }\end{array}$ & Positiva & Positiva \\
\hline
\end{tabular}

Fonte: Elaborada pelos autores (2015).

\section{DISCUSSÃO DOS PRINCIPAIS RESULTADOS}

\subsection{ASPECTOS CULTURAIS QUE INFLUENCIAM NA NEGOCIAÇÃO INTERNACIONAL}

Revista Eletrônica de Estratégia \& Negócios, Florianópolis, v.9, n.1, jan./abr. 2016. 
Todos experts entrevistados acreditam que, quando um negociador de outra nacionalidade está envolvido na negociação, o fator cultural passa a ser determinante. Então, uma posição de respeito e de compreensão deve ser adotada, a fim de evitar constrangimentos ou potenciais conflitos e aumentar as chances de êxito da negociação. Esta perspectiva está consonante a Gulbro e Herbig (1996), Ang e Teo (1997) e Wilken, Jacob e Prime (2013), que salientam que qualquer negociação internacional de sucesso exige a identificação, a compreensão, a aceitação e o respeito com as características culturais dos negociadores envolvidos, logicamente, no contexto de tal atividade, abarcadas pelas características situacionais inerentes ao trabalho desempenhado pelos negociadores (HAUFF; RICHTER; TRESSIN, 2015).

Ao serem questionados sobre as características culturais que têm influência na negociação internacional, todos os experts entrevistados mencionaram a distância de poder, representada pelas diferentes percepções que cada cultura tem sobre as relações de poder e a hierarquia existente. Para Hofstede (1994) e Hofstede, Hofstede e Minkov (2010), nem todos os indivíduos são iguais na sociedade, e a distância de poder expressa o nível de aceitação de cada cultura sobre tais desigualdades. Os experts acreditam que o negociador internacional deve ser capaz de entender como funcionam os níveis hierárquicos em cada país, o que pode ajudá-lo a direcionar seus esforços às pessoas corretas. Além disso, a grande maioria dos entrevistados acredita que os graus de integração dos indivíduos em grupos pode afetar a negociação internacional, o que converge com uma das dimensões propostas por Hofstede (1994), individualismo versus coletivismo. Os experts afirmam que, em culturas mais individualistas, o negociador tende a ter mais autonomia no processo de tomada de decisões e um maior foco nos resultados. Já em culturas coletivistas as decisões são tomadas apenas com o aval de todo o grupo e o principal foco está na construção de laços e de relacionamentos.

A importância da dimensão masculinidade versus feminilidade, também proposta por Hofstede (1994), foi igualmente ratificada pelos experts. Eles afirmaram que, em determinadas culturas, o negociador preza apenas por seu próprio sucesso e realização, mesmo que isso cause um desequilíbrio entre as partes negociantes. Hofstede (1994) aponta que estes são valores almejados pelas culturas nas quais predomina a masculinidade, em oposição às culturas mais femininas, que prezam pela cooperação, equilíbrio e preocupação Revista Eletrônica de Estratégia \& Negócios, Florianópolis, v.9, n.1, jan./abr. 2016. 
com a outra parte, dando à negociação um caráter de maior reciprocidade entre as partes envolvidas (MATANDA; FREEMAN, 2009; CHUAH; HOFFMANN; LAMER, 2014).

A dimensão aversão à incerteza, proposta por Hofstede (1994), e corroborada por Sobral, Carvalhal e Almeida (2008), também foi mencionada pelos experts como uma característica que pode afetar sobremaneira a negociação internacional, e que pode torná-la mais lenta ou mais fluída, dependendo do sistema burocrático dos países com os quais se está negociando. Isto está de acordo com o que dizem os autores, que afirmam que negociadores provenientes de culturas com mais aversão ao risco tendem a solicitar que todos os termos negociados sejam formalizados, enquanto negociadores de culturas com menos aversão ao risco não têm receio de tomar as decisões mais rapidamente e impulsivamente (HOFSTEDE, 1994; 2013; HOFSTEDE; USUNIER, 2003; HOFSTEDE; HOFSTEDE; MINKOV, 2010).

Além disso, os experts também reconheceram a importância da orientação de longo ou curto prazo na negociação internacional e, consequentemente, em seus resultados. De acordo com Hofstede (2013) e Hofstede, Hofstede e Minkov (2010), negociadores provenientes de culturas com orientação em longo prazo se preocupam mais com os resultados futuros, enquanto que negociadores de culturas com orientação de curto prazo com resultados imediatos. Os experts afirmam que este fator pode ter grande impacto na negociação e que, se os negociadores não alinharem seus valores e objetivos neste sentido, não é possível chegar a um entendimento quanto ao futuro do negócio. E tal circunstância repercutirá diretamente nos resultados provenientes para os parceiros de negócio envolvidos (ANG; TEO, 1997; CULLEN; PARBOTEEAH, 2010; CZINKOTA; RONKAINEN, 2011; van TULDER, 2013).

\subsection{CARACTERÍSTICAS CULTURAIS BRASILEIRAS}

Sobre as características culturais brasileiras, os experts e os negociadores entrevistados foram unânimes ao afirmar que a hierarquia é uma das características mais fortes e notáveis dentro das empresas no Brasil. Um dos experts menciona o fato de que o dono ou gestor da empresa, quando presente nas negociações internacionais é, não raro, o único tomador de decisões. Isto vai ao encontro dos estudos de Hofstede (2013), que apontam que a hierarquia deve ser respeitada e as desigualdades entre as pessoas são Revista Eletrônica de Estratégia \& Negócios, Florianópolis, v.9, n.1, jan./abr. 2016. 
aceitáveis no Brasil, e também com o que propõe Motta (1997), ao afirmar que, dentro das organizações brasileiras, há uma grande centralização de poder. Os experts acreditam que este seja um aspecto negativo da cultura brasileira, uma vez que esta centralização de poder gera a inibição das ideias e de opiniões dos funcionários de outros escalões (níveis). Boa parte dos negociadores entrevistados concordou com este ponto de vista. E isto é, marcantemente, uma característica cultural e organizacional que afeta como uma empresa se estrutura e age, por meio de seus gestores, em um processo negocial (BARON, 1989; DOSOGLU-GUNER, 2001; HARRIS; CARR, 2008).

A maior parte dos experts entrevistados colocou que o nepotismo é uma prática corriqueira no Brasil, o que está de acordo com os estudos de Motta (1997), que afirma que é comum, nas organizações brasileiras, o favorecimento de parentes e de amigos na nomeação de cargos. Os negociadores entrevistados afirmam que esta prática é comum em diversas culturas, não apenas na brasileira. Parte dos entrevistados acredita que esta seja uma conduta negativa, pois desvaloriza o mérito e a capacidade dos indivíduos, enquanto que outros creem que não há mal maior em privilegiar as pessoas mais próximas, levando-se em conta que a confiança e a qualificação profissional têm igual importância no ambiente empresarial. E estas questões, caso mal configuradas e geridas, podem explicitar conflitos que, em uma negociação internacional pode se exacerbar e repercutir na não concretização de negócios ou em resultados insatisfatórios para os envolvidos (TURNER; KLEINER, 2001; TJEMKES; VOS; BURGERS, 2012; CHUAH; HOFFMANN; LAMER, 2014).

Quanto aos valores masculinos, como busca por lucratividade e rentabilidade, sucesso e bens materiais, e valores femininos, relacionados à busca por qualidade de vida e preocupação com os outros, boa parte dos experts e negociadores entrevistados acredita que os membros da cultura brasileira têm maior apreço pelos princípios femininos. De acordo com os estudos de Hofstede (2013), existe um equilíbrio no Brasil entre estes polos, como uma leve inclinação para a feminilidade, o que vai ao encontro da percepção dos entrevistados. Segundo um dos experts, o estilo de negociação brasileiro está voltado para a concordância e resultados positivos para ambas as partes. Os negociadores acreditam que o brasileiro é muito preocupado com a outra parte e flexível nos negócios, e que valoriza as horas de lazer e não é ligado somente ao status e a bens materiais. Além disso, os entrevistados mencionaram que as mulheres estão ascendendo no mercado de trabalho e Revista Eletrônica de Estratégia \& Negócios, Florianópolis, v.9, n.1, jan./abr. 2016. 
que não há tanto machismo no Brasil quanto em outros países. Tal evidência converge com o proposto por Motta (1997), que defendem que, nas culturas com maior orientação para os valores femininos, homens e mulheres são tratados de maneira mais igualitária, inclusive no ambiente empresarial. Cabe ressaltar que todos os entrevistados acreditam que esta é uma característica positiva.

Em relação à alta aversão à incerteza existente no Brasil, e proposta nos estudos de Hofstede (2013), o que poderia ser minimizado pela existência de uma legislação mais rígida, os entrevistados são unânimes ao afirmar que a existência de leis, regras e burocracia é muito grande na sociedade brasileira, e que este é um elemento negativo principalmente para os negócios. Eles acreditam que os sistemas brasileiros são mal estruturados e não funcionam apropriadamente, o que acarreta em demandas de tempo e dinheiro que não seriam necessárias em outros contextos. Os entrevistados acreditam que se houvesse uma desburocratização dos sistemas, isto geraria um aumento da competição e da competitividade e, consequentemente, da qualidade dos produtos e/ou serviços brasileiros.

Tratando-se da orientação de longo prazo versus orientação de curto prazo, os entrevistados apresentaram ideias contrárias àquelas propostas pelos autores. Segundo grande parte dos entrevistados, o brasileiro é afoito e almeja resultados de curto prazo, o que não é positivo para os negócios internacionais, que demandam planejamento e estratégias voltadas para o longo prazo (ANG; TEO, 1997; CZINKOTA; RONKAINEN, 2020). Vale destacar que os estudos de Hofstede (2013) mostram o contrário, e posicionam o Brasil entre as sociedades orientadas ao longo prazo. De acordo com alguns dos entrevistados, uma das principais explicações pela necessidade que o brasileiro tem por resultados rápidos, imediatos, é a crise vivida no período inflacionário severo das décadas de 80 e 90 . Isto pode explicar a diferença entre a percepção dos entrevistados e a base conceitual, já que a pesquisa de Michael Bond, que serviu como base para as conclusões de Hofstede (2013), foi aplicada no ano de 1985 (HOFSTEDE; HOFSTEDE; MINKOV, 2010), sendo possível que a orientação do brasileiro tenha sido fortemente afetada após o período da crise anteriormente mencionada.

Em termos de orientação do tempo, experts e negociadores concordam que o Brasil opera sob um sistema de tempo policrônico, conforme Sobral, Carvalhal e Almeida (2008). 
Os entrevistados, assim como os autores, percebem que os brasileiros não têm preocupação em manter seus horários e programações e são capazes de falar sobre vários tópicos ao mesmo tempo. Em relação à impontualidade, os entrevistados expuseram que o brasileiro não é rigoroso no cumprimento de horários, o que vai ao encontro de Turner e Kleiner (2001). Alguns dos entrevistados acreditam tal comportamento até possa ser visto como algo positivo, pois denota flexibilidade e capacidade de se adequar às necessidades. Porém, outros acreditam que isto é uma característica negativa, pois atestam que o brasileiro não é capaz de se preparar ou se planejar com antecedência para os seus compromissos. Tratando-se da orientação de espaço, os entrevistados afirmam que o contato físico (toques) é constante durante o processo de comunicação com o brasileiro. Para Sobral, Carvalhal e Almeida (2008), é normal, no Brasil, que as pessoas se toquem durante a comunicação. Inclusive, Freitas (1997) relata que beijos e abraços apertados são comuns no cotidiano brasileiro. Os entrevistados têm opiniões contrárias sobre tal comportamento. Alguns dos entrevistados pensam que é uma atitude muito invasiva e outros a veem como uma demonstração positiva de afeto e de confiança.

O jeitinho brasileiro foi apontado como uma característica cultural brasileira positiva por grande parte dos entrevistados. De acordo com Freitas (1997), o jeitinho é sinônimo de flexibilidade, dinamismo e capacidade de rápida adaptação. Tal afirmativa converge com o que dizem os experts e grande parte dos negociadores entrevistados, que elogiam a habilidade do brasileiro de se ajustar às situações menos ideais. Segundo um dos experts, o jeitinho brasileiro é uma forma de adaptação das pessoas às leis e às regras rígidas do Brasil, que não levam em consideração as particularidades de cada uma das regiões brasileiras, subculturas e comportamentos regionais ou locais. Ele ainda afirmou que, se um estrangeiro não compreende a realidade do Brasil, poderá interpretar o jeitinho como algo negativo, uma espécie de comportamento malevolente ou oportunista. Isto pode explicar a crença de um dos negociadores, que afirmou que o jeitinho brasileiro é negativo e atrapalha nos negócios. Independentemente de seu caráter positivo ou negativo, o jeitinho brasileiro, segundo Barbosa (1992), pode ser compreendido como a arte de ser mais igual que os outros.

Uma última característica apontada por boa parte dos entrevistados, é o complexo de inferioridade que permeia a sociedade brasileira e que foi apontado por Caldas (1997). Os Revista Eletrônica de Estratégia \& Negócios, Florianópolis, v.9, n.1, jan./abr. 2016. 
experts acreditam que o brasileiro é propenso a ser muito crítico com a sua própria cultura, o que pode ser prejudicial na negociação internacional, uma vez que ele tende a aceitar, mais facilmente, o que é proposto pelas culturas dominantes. Eles acreditam que tal percepção aos poucos está mudando, e que o brasileiro já é mais favorável aos produtos e/ou serviços oferecidos no país. Os negociadores concordam que esta atitude seja muito negativa e, enquanto alguns acreditam que este complexo seja reflexo da realidade, muito em função do processo de colonização do país, outros creem que ele existe apenas no imaginário brasileiro.

\section{CONSIDERAÇÕES FINAIS}

Com base na literatura e na presente pesquisa, foi possível verificar que as negociações internacionais estão sujeitas ao impacto da cultura dos negociadores participantes. Dessa forma, o negociador internacional deve ser capaz de identificar e compreender as características culturais de cada país antes de iniciar qualquer processo de negociação, sendo este elemento essencial para uma relação exitosa. A presente pesquisa pôde evidenciar que, de maneira geral, os experts brasileiros sobre os temas cultura e negociação internacional, além de negociadores de diferentes nacionalidades, apresentam percepções muito similares quanto às características culturais brasileiras e seu impacto, positivo ou negativo, na negociação internacional. É possível inferir, por exemplo, que a cultura brasileira é caracterizada por uma grande distância de poder, alta aversão à incerteza, apoio ao nepotismo, sistema de tempo policrônico, apreço pelo contato físico, entre outros aspectos. Tais características têm impacto direto nas relações entre executivos brasileiros e negociadores provenientes de outros países, e é imprescindível compreendê-las a fim de estabelecer relações respeitosas e colaborar, assim, para uma parceria forte e proveitosa entre as partes negociantes, gerando bons resultados.

A partir do depoimento de alguns dos entrevistados, percebeu-se a falta de preparo do negociador brasileiro para lidar no ambiente internacional. Neste sentido, o presente estudo colabora para o aprimoramento do comportamento profissional dos executivos brasileiros, ajudando-os a identificar quais são suas características culturais percebidas como negativas - como a grande distância de poder e a orientação de curto prazo - e tentar amenizá-las, na medida do possível, visando facilitar o entendimento entre as partes 
negociantes. Além disso, o estudo pode ajudar a instigar executivos brasileiros a identificar e utilizar os pontos fortes de sua cultura, tais como a abertura e a paixão do povo, a seu favor durante as negociações.

De qualquer forma, há toda uma diversidade cultural nacional (CORRÊA, 2008) e internacional (ACUFF, 2008; DOURADO FILHO; SEBEN, 2010), e que repercute, bem ou mal, em comportamentos na vida e no mundo dos negócios (KARRASS, 1996), bem como em um estilo de negociar característico do brasileiro (MOTTA, 1997; PRATES; BARROS, 1997; MORELLI et al., 2002; SOBRAL; CARVALHAL; ALMEIDA, 2008; HOFSTEDE, 2013) e em relação a negociadores de outras nacionalidades (SHIMUTWIKENI, 2011; KHAKHAR; RAMMAL, 2013; CHUAH; HOFFMANN; LAMER, 2014), respeitando-se os traços interculturais atinentes aos processos de negociação (GULBRO; HERBIG, 1996; SIMINTIRAS; THOMAS, 1998; HARRIS; CARR, 2008; WILKEN; JACOB; PRIME, 2013; HAUFF; RICHTER; TRESSIN, 2015).

Por fim, é oportuno comentar que, como é comum a todas as pesquisas, este estudo também apresenta limitações. Todos os experts entrevistados residem na região Sul do Brasil e os negociadores internacionais participantes da pesquisa fazem negócios apenas com as regiões Sul e Nordeste. Considerando que o Brasil é um país de proporções continentais e, portanto, as diferenças culturais entre uma região e outra são representativas, as conclusões do presente estudo podem não ser aplicáveis ao Brasil como um todo. Como sugestão, indica-se que novos estudos nesta área sejam focados em outras regiões do Brasil.

Além disso, é possível que as percepções dos experts entrevistados sejam afetadas devido ao fato de todos serem brasileiros. Assim sendo, recomenda-se que pesquisas deste mesmo cunho sejam realizadas com experts de outras nacionalidades, que porventura possam ter outros valores e princípios, crenças, percepções ou comportamentos no âmbito do processo de negociações internacionais. Também seria relevante a utilização de outros métodos de pesquisa, como, por exemplo, a utilização de focus groups (grupos focados) (RIBEIRO, 2003; RIBEIRO; MILAN, 2004) ou abordagens etnográficas (BERNARD; RYAN, 2010; HENNINK; HUTTER; BAILEY, 2011).

Ainda assim, espera-se que esta pesquisa possa incentivar negociadores brasileiros a se preparar adequadamente ao ambiente multicultural resultante da internacionalização Revista Eletrônica de Estratégia \& Negócios, Florianópolis, v.9, n.1, jan./abr. 2016. 
das empresas e do mercado brasileiro, além de ajudar aos negociadores estrangeiros que desejam fazer negócios com o Brasil, compreendendo nossa cultura e nossa forma de negociar.

\section{REFERÊNCIAS}

ACUFF, F. L. How to negotiate anything with anyone anywhere around the world. New York: AMA - American Management Association, 2008.

ANG, S. H.; TEO, G. Effects of time process orientation, agreement preferences and attitude towards foreign businessmen on negotiation adaptation. International Business Review, v. 6, n. 6, p. 624-640, 1997.

BARBOSA, L. O jeitinho brasileiro: a arte de ser mais igual que os outros. Rio de Janeiro: Campus, 1992.

BARDIN, L. Análise de conteúdo. Lisboa: Edição 70, 2004.

BARON,R.Personalityandorganizationalconflict:effectsoftypeabehaviorandself-monitoring. Organizational Behavior and Human Decision Processes, v. 44, n. 2, p. 281-296, 1989.

BERNARD, H. R.; RYAN, G. W. Analyzing qualitative data: systematic approaches. Thousand Oaks: Sage Publications, 2010.

CALDAS, M. Santo de casa não faz milagre: condicionantes nacionais e implicações organizacionais da fixação brasileira pela figura do estrangeiro. In:MOTTA,F.C.P.; CALDAS, M. (org.). Cultura organizacional e cultura brasileira.SãoPaulo:Atlas, 1997.cap.4, p. 73-93.

CAVUSGIL, S. T.; KNIGHT, G.; RIESENBERGER, J. R. Negócios internacionais: estratégia, gestão e novas realidades. São Paulo: Pearson / Prentice Hall, 2010.

CHUAH, S. H.; HOFFMANN, R.; LAMER, J. Chinese values and negotiation behaviour: a bargaining experiment. International Business Review, v. 23, n. 6, p. 1.203-1.211, 2014.

COHEN, H. Você pode negociar qualquer coisa. Rio de Janeiro: Record, 2004.

CORRÊA, R. L. T. Cultura e diversidade. Curitiba: Ibpex, 2008.

CULLEN, J. B.; PARBOTEEAH, K. P. International business: strategy and the multinational company. New York: Routledge, 2010.

CZINKOTA, M. R.; RONKAINEN, I. A. Global business: positioning ventures ahead. New York: Routledge, 2011.

DOSOGLU-GUNER, B. Can organizational behavior explain the export intention of firms? International Business Review, v. 10, n. 1, p. 71-89, 2001. 
DOURADO FILHO, F.; SEBBEN, A. Os nortes da bussola: manual para conviver e negociar com culturas estrangeiras. Porto Alegre: Artes e Ofícios, 2010.

FREITAS, A. B. Traços brasileiros para uma análise organizacional. In: MOTTA, F. C. P.; CALDAS, M. (org.). Cultura organizacional e cultura brasileira. São Paulo: Atlas, 1997. cap. 2, p. 38-54.

GULBRO, R.; HERBIG, P. Cross-cultural negotiating processes. Industrial Management \& Data Systems, v. 96, n. 3, p. 17-23, 1996.

HALL, E. T. Beyond culture. New York: Anchor Books Editions, 1989.

HARRIS, S.; CARR, C. National cultural values and the purpose of businesses. International Business Review, v. 17, n. 1, p. 103-117, 2008.

HAUFF, S.; RICHTER, N. F.; TRESSIN, T. Situational job characteristics and job satisfaction: the moderating role of national culture. International Business Review, v. 24, n. 4, p. 710-723, 2015.

HENNINK, M.; HUTTER, I.; BAILEY, A. Qualitative research methods. Thousand Oaks: Sage Publications, 2011.

HOFSTEDE, G. The business of international business is culture. International Business Review, v. 3, n. 1, p. 1-14. 1994.

HOFSTEDE, G. National culture: Brazil. Disponível em: http://geerthofstede.com/brazil.html. Acesso em: 10 out. 2013.

HOFSTEDE, G.; HOFSTEDE G. J.; MINKOV, M. Cultures and organizations: software of the mind. New York: McGraw-Hill, 2010.

HOFSTEDE, G.; USUNIER; J. C. Hofstede's dimensions of culture and their influence on international business negotiations. In: GHAURI, P. N.; USUNIER; J. C. (eds.). International business negotiations. Kidlington: Elsevier, 2003. chapter 6, p. 137-153.

KHAKHAR, P.; RAMMAL, H. G. Culture and business networks: international business negotiations with Arab managers. International Business Review, v. 22, n. 3, p. 578-590, 2013.

KARRASS, C. L. In business as in life: you don't get what you deserve, you get what you negotiate. Beverly Hills: Copyright, 1996.

KING, N.; HORROCKS, C. Interviews in qualitative research. Thousand Oaks: Sage Publications, 2010.

KRIPPENDORFF, K. Content analysis: an introduction to its methodology. $3^{\text {rd }}$ edition. Thousand Oaks: Sage Publications, 2013.

KVALE, S.; BRINKMANN, S. Interviews: learning the craft of qualitative research interviewing. $2^{\text {nd }}$ edition. Thousand Oaks: Sage Publications, 2009. 
LIN, X.; MILLER, S. J. Negotiation approaches: direct and indirect effect of national culture. International Marketing Review, v. 20, n. 3, p. 286-303, 2003.

MARTINELLI, D. P.; VENTURA, C. A. A.; MACHADO, J. R. Negociação internacional. São Paulo: Atlas, 2004.

MATANDA, M. J.; FREEMAN, S. Effect of perceived environmental uncertainty on exporterimporter inter-organisational relationships and export performance improvement.

International Business Review, v. 18, n. 1, p. 89-107, 2009.

MDIC-Ministério do Desenvolvimento, Indústria e Comércio Exterior. MDIC divulga material sobreos 200 anos do comércio exterior brasileiro. 2008. Disponívelem: www.desenvolvimento .gov.br/sitio/interna/noticia.php?area= 5\&noticia=8219. Acesso em: 10 abr. 2015.

MILES, G. L. Crime, corruption and multinational business. International Business. Washington: Bucking Institution, 1995.

MILES, M. B.; HUBERMAN, A. M.; SALDAÑA, J. Qualitative data analysis: a methods sourcebook. $3^{\text {rd }}$ edition. Thousand Oaks: Sage Publications, 2014.

MORELLI, G.; CAVALCANTI, B. C.; LAGES, V. N.; PALUMBO; S. Cara brasileira: a brasilidade nos negócios - um caminho para o "made in Brazil". Brasília: SEBRAE, 2002.

MOTTA, F. C. P. Cultura e organizações no Brasil. In: MOTTA, F. C. P.; CALDAS, M. (org.). Cultura organizacional e cultura brasileira. São Paulo: Atlas, 1997. cap. 1, p. 25-37.

PRATES, M. A.S.; BARROS, B.T.O estilo brasileiro de administrar: sumário de um modelo de ação cultural brasileiro com base na gestão empresarial. In: MOTTA, F. C. P.; CALDAS, M. (org.). Cultura organizacional e cultura brasileira. São Paulo: Atlas, 1997. cap. 3, p. 55-69.

REMLER, D. K.; VAN RYZIN, G. G. Research methods in practice: strategies for description and causation. Thousand Oaks: Sage Publications, 2011.

RIBEIRO, J. L. D. (ed.). Grupos focados: teoria e aplicações. Porto Alegre: FEEng/UFRGS, 2003.

RIBEIRO, J. L. D.; MILAN, G. S. Planejando e conduzindo entrevistas individuais. In: RIBEIRO, J. L. D.; MILAN, G. S. (eds.). Entrevistas individuais: teoria e aplicações. Porto Alegre: FEEng/UFRGS, 2004. cap. 1, p. 9-22.

ROSS, W. T.; ROBERTSON, D. C. Compound relationship between firms. Journal of Marketing, v. 71, n. 1, p. 108-123, 2007.

SCHREIER, M. Qualitative content analysis in practice. London: Sage Publications, 2012.

SCOTT, G.; GARNER, R. Doing qualitative research: designs, methods, and techniques. Upper Saddle River: Pearson, 2013. 
SHIMUTWIKENI, N. The impact of culture in international business negotiations: special reference to China and United States of America. Centre For Energy, Petroleum And Mineral Law And Policy Gateway Annual Review, v. 14, p. 1-8, 2011.

SIMINTIRAS, A. C.; THOMAS, A. H. Cross-cultural sales negotiations: a literature review and research prepositions. International Marketing Review, v. 15, n. 1, p. 10-28. 1998.

SOBRAL, F.; CARVALHAL, E.; ALMEIDA, F. The influence of culture on negotiation styles of Brazilian executives. Management Research: The Journal of the Iberoamerican Academy of Management, v. 6, n. 2, p. 107-119, 2008.

TJEMKES, B.; VOS, P.; BURGERS, K. Strategic alliance management. New York: Routledge, 2012.

TURNER, W.; KLEINER, B. H. What managers must know to conduct business in Brazil. Management Research News, v. 24, v. 3, p. 72-75, 2001.

van TULDER, R. Global business: managing risk and responsibility. 2 Ed. London: Routledge, 2013.

WALTER, S. A.; FREGA, J. R. Repatriados brasileiros de transnacionais: fatores relevantes para sua permanência. Revista Eletrônica de Estratégia \& Negócios, v. 8, n. 1, p. 3 - 31, abr. 2015

WILKEN, R.; JACOB, F.; PRIME, N. The ambiguous role of cultural moderators in intercultural business negotiations. International Business Review, v. 22, n. 4, p. 736-753, 2013. 